JURNAL 『匿NNOSAINS

VOLUME 2

No. 1, 22 Desember 2012

Halaman 1-70

\title{
ANALISIS DAN PROFIL \\ TINGKAT KEBUGARAN MAHASISWA JURUSAN TEKNIK MESIN DAN INDUSTRI UNIVERSITAS GADJAH MADA YOGYAKARTA
}

\author{
Herianto dan Chusla Rosdiana Dewi \\ Jurusan Teknik Mesin dan Industri Fakultas Teknik Universitas Gadjah Mada \\ Email: herianto@ugm.ac.id
}

\begin{abstract}
Aerobic fitness can be used as a health indicator. The purpose of this study is to investigate the effect of Body Mass Index, gender, and physical activity on the aerobic fitness. Twenty females and 27 males students in range of $20 \pm 1.2$ years old, height $164 \pm 8.95 \mathrm{~cm}$, and weight $58.23 \pm 9.5 \mathrm{~kg}$ that meet inclusion criteria were used as subject that measured in Ergonomics Laboratory Gadjah Mada University within room temperature $25-26^{\circ} \mathrm{C}$ and $40-50 \%$ in humidity. Four methods of indirect measurement ( $\mathrm{VO}_{2}$ max as an output) is used to measure aerobic fitness: nonexercise skinfold measurements and Body Mass Index, Astrand bicycle, treadmill, and the fitness index Harvard Step Test performed on different days. The results showed that gender $\left(r_{s}=0.838\right.$ on the nonexercise BMI) and BMI $\left(r_{s}=-0.677\right.$ on the Astrand method) effect on aerobic fitness. The average value of $\mathrm{VO}_{2} \max (\mathrm{ml} . \mathrm{kg}-1 . \mathrm{min}$ in-1) is achieved from each method. For male, Astrand bicycle $=53.24 \pm 7.82$, treadmill $=38.43 \pm 9,05, B M I=44.85 \pm 3.45,42.49 \pm 3.38=$ skinfold. For women, Astrand bicycle $=47.86 \pm 8.59, \pm 5.73$ treadmill $=34.1, B M I=34.25 \pm 2.46,34.63 \pm 2.51=$ skinfold .
\end{abstract}

Keywords: aerobic fitness, Body mass index, physical activity

\begin{abstract}
ABSTRAK
Salah satu tolak ukur kesehatan adalah kebugaran aerobik. Tujuannya untuk mengetahui pengaruh Body Mass Index, jenis kelamin, dan aktivitas fisik terhadap kebugaran aerobik. Sebanyak 20 orang perempuan dan 27 orang laki-laki yang telah memenuhi kriteria inklusi diuji kebugarannya di Laboratorium Ergonomika Universitas Gadjah Mada dengan temperatur $25-26^{\circ} \mathrm{C}$ dan kelembaban udara $40-50 \%$. Empat metode pengukuran tidak langsung dengan output $\mathrm{VO}_{2}$ max yang digunakan, yaitu pengukuran nonexercise skinfold dan Body Mass Index, sepeda Astrand, treadmill, dan indeks kebugaran Hardvard Step Test. Hasil menunjukkan bahwa jenis kelamin ( $\mathrm{r}=0,838$ pada metode nonexercise BMI) dan BMI $(\mathrm{r}=-0,677$ pada metode Astrand) berpengaruh pada kebugaran aerobik. Rata-rata nilai $\mathrm{VO}_{2} \max \left(\right.$ dalam $\mathrm{ml} \cdot \mathrm{kg}^{-1} \cdot \mathrm{min}^{-1}$ ) yang dicapai dari masing-masing metode yaitu pada lakilaki untuk metode sepeda Astrand $=53,24 \pm 7,82$, treadmill $=38,43 \pm 9,05$, BMI $=44,85 \pm 3,45$, skinfold $=42,49 \pm 3,38$. Untuk perempuan, metode sepeda Astrand $=47,86 \pm 8,59$, treadmill $=34,1 \pm 5,73$, BMI $=$ $34,25 \pm 2,46$, skinfold $=34,63 \pm 2,51$.
\end{abstract}

Kata kunci: kebugaran aerobik, body mass index, aktivitas fisik 


\section{PENGANTAR}

Keselamatan dan Kesehatan Kerja (K3) merupakan hal penting dalam dunia kerja. Menurut perkiraan ILO, setiap tahun di seluruh dunia 2 juta orang meninggal karena masalah-masalah akibat kerja. Di samping itu, setiap tahun ada 270 juta pekerja yang mengalami kecelakaan dan 160 juta yang terkena penyakit akibat kerja. Pemeriksaan kesehatan (medical check up) adalah suatu bentuk tindakan pencegahan dan sering digunakan untuk mendeteksi adanya suatu penyakit secara dini agar tidak mengganggu posisi pekerjaan yang akan dipegang calon karyawan. Beberapa bagian penting dari tes kesehatan adalah pengukuran antropometri dan tes fisiologi (fungsi sistem dalam tubuh). Salah satu dari fungsi sistem tubuh terpenting untuk pekerjaan adalah ketahanan aerobik karena beberapa bagian dari pekerjaan seperti naik turun tangga maupun aktivitas lain seperti memadamkan kebakaran sangat membutuhkan ketahanan aerobik (aerobic endurance) dalam pelaksanannya. Sebagai contoh, respon detak jantung ketika bekerja merupakan indeks level suatu pekerjaan yang menunjukkan tingkat kemampuan fisik seseorang dalam melakukan pekerjaan tersebut. Selain detak jantung, jumlah maksimum volume oksigen merupakan variabel fisiologis yang digunakan untuk mengevaluasi kapasitas kemampuan fisik pekerja disesuaikan kondisi fisik yang dibutuhkan (job demand) dalam pekerjaan tersebut (Baumgartner dkk, 2007). Kebugaran jasmani seseorang merupakan salah satu faktor yang menentukan kesehatan. Kebugaran jasmani adalah kemampuan seseorang menyelesaikan tugas sehari-hari dengan tanpa pengeluaran energi yang cukup besar guna memenuhi kebutuhan geraknya dan menikmati waktu luang serta untuk memenuhi keperluan darurat bila sewaktu-waktu diperlukan (Sajoto, 1988). Sementara daya tahan kardiorespirasi sebagai kemampuan jantung, paru, dan sistem peredaran darah untuk berfungsi secara efisien dalam tempo yang cukup tinggi selama periode waktu tertentu. Kebugaran kardiorespirasi diukur dari kapasitas aerobik (Lutan, 2001). Penelitian ini merupakan langkah awal untuk mengetahui profil dan variasi kebugaran aerobik ditinjau dari faktor jenis kelamin, level aktivitas fisik, dan Body Mass Index (BMI) serta metode pengukuran kebugaran yang paling tepat untuk mahasiswa JTMI sebagai persiapan untuk menempuh prasyarat kesehatan dalam dunia kerja.

Tulisan ini mengulas tentang preexperiment design. Subyek pengamatan adalah mahasiswa Jurusan Teknik Mesin dan Industri Universitas Gadjah Mada sejumlah 20 orang perempuan dan 27 orang laki-laki dengan karakterisitik rata-rata usia 20 $\pm 1,2$ tahun, tinggi badan $164 \pm 8,95 \mathrm{~cm}$, dan berat badan $58,23 \pm 9,5 \mathrm{~kg}$. Subyek yang termasuk dalam kriteria inklusi yang diperkenankan untuk diuji, yaitu tidak merokok, bukan peminum alkohol, tidak hamil, menstruasi, dan tidak menderita penyakit kardiovaskular serta muskuloskeletal. pengamatan dilakukan selama 3 hari di dalam ruang Laboratorium Ergonomika JTMI UGM dengan $\mathrm{T}=25-26^{\circ} \mathrm{C}$ dan kelembaban udara 40-50\% (Grandjean, 1986) dalam lima metode yang berbeda yaitu pengukuran $\mathrm{VO}_{2}$ max melalui nonexercise model: skinfold dan Body Mass Index, exercise model: sepeda Astrand, Balke protocol treadmill, dan pengukuran indeks kebugaran Hardvard Step Test. Kelima metode merupakan pengukuran tidak langsung dengan melihat respon fisiologis (denyut jantung) dan waktu tempuh saat tes sebagai input mencari nilai $\mathrm{VO}_{2}$ max yang telah dikorelasikan dengan pengukuran $\mathrm{VO}_{2}$ max secara langsung.

Penentuan nilai prediksi $\mathrm{VO}_{2}$ max melalui pengukuran BMI dilakukan menggunakan persamaan dengan melibatkan faktor umur, BMI, dan SRPA (Astrand, dkk: 2003). Prediksi pada metode skinfold dilakukan dengan menjumlahkan tebal kulit daerah triceps, suprailiaca, dan abdomen yang diukur menggunakan skinfold calliper (Indriati, 2011). Jumlah tebal lipatan kulit ini digunakan sebagai input untuk menghitung persentase 
lemak tubuh (Atmadja dan Doewes, 1995) dan nilai prediksi $\mathrm{VO}_{2}$ max dari persentase lemak tubuh (Astrand, dkk: 2003). Metode sepeda Astrand menggunakan uji submaksimal di mana subyek mengayuh sepeda statis selama minimum enam menit dengan pembebanan tertentu dan bertahap (Widaninggar dkk, 2002). Uji treadmill menggunakan protokol Balke. $\mathrm{VO}_{2} \max$ dihitung dari persamaan waktu tempuh pada lintasan lari (Astrand dkk, 2003). Pada Hardvard Step Test, responden naik turun bangku setinggi \pm 17 inch selama maksimal 5 menit, kemudian dihitung physical fitness index (PFI) (Widaninggar dkk, 2002). Aktivitas fisik diukur menggunakan short form International Physical Activity Questionnaire (IPAQ). Penentuan level aktivitas berdasarkan volume aktivitas dalam jangka waku tertentu selama tujuh hari ke belakang dalam satuan METs-minute (IPAQ Research Committee, 2005). Beberapa uji statistik antara lain uji Krusskall-Wallis, uji Spearman, dan uji Friedman digunakan untuk menganalisa korelasi faktor BMI, jenis kelamin, dan aktivitas fisik terhadap nilai $\mathrm{VO}_{2} \max$ (Sopiyudin, 2001).

\section{PEMBAHASAN}

Dari 47 responden yang diuji terdapat variasi level aktivitas fisik pada mahasiswa Jurusan Teknik Mesin dan Industri yang dilihat dari total volume aktivitas, yaitu 17\% mahasiswa memiliki level aktivitas yang rendah, 57\% sedang, dan 26\% tinggi.

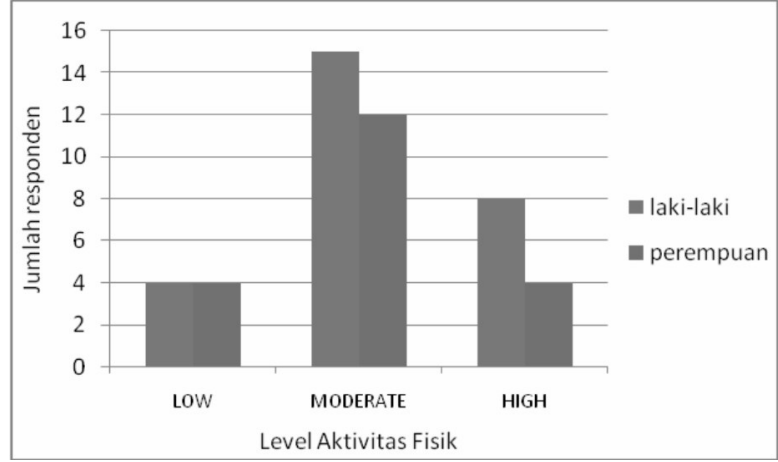

Gambar 1. Profil Level Aktivitas Fisik Mahasiswa JTMI

Selain variasi aktivitas juga terdapat variasi Body Mass Index yaitu 13\% di jumlah mahasiswa memiliki BMI dengan kategori underweight, $72 \%$ normal, $13 \%$ overweight, dan $2 \%$ obesity 1 .

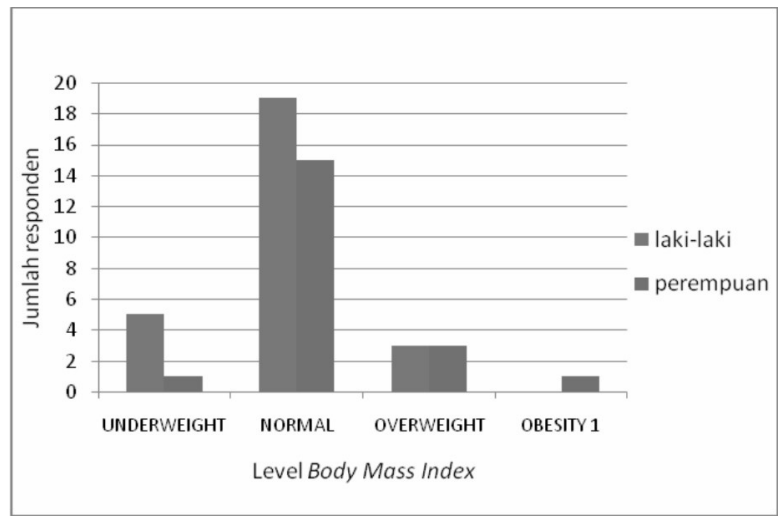

Gambar 2. Profil Body Mass Index Mahasiswa JTMI UGM

Tabel 1. Signifikansi $\mathrm{VO}_{2}$ max dengan Faktor Jenis Kelamin, Body Mass Index, dan Aktivitas fisik

\begin{tabular}{|l|l|c|c|c|c|}
\hline \multirow{2}{*}{ FAKTOR } & \multicolumn{3}{|c|}{ VO2 MAX DARI UJI } & PFI HARDVARD STEP \\
\cline { 2 - 5 } & SKINFOLD & BMI & ASTRAND & TREADMILL & TEST \\
\hline JENIS KELAMIN & $\mathbf{p}=\mathbf{0 , 0 0 0}$ & $\mathbf{p}=\mathbf{0 , 0 0 0}$ & $\mathbf{p}=\mathbf{0 , 0 4 8}$ & $\mathrm{p}=0,156$ & $\mathbf{p}=\mathbf{0 , 0 0 0}$ \\
\hline AKTIVITAS FISIK & $\mathrm{p}=0, \mathbf{0 0 0}$ & $\mathrm{p}=0,352$ & $\mathrm{p}=0,226$ & $\mathrm{p}=0,105$ & $\mathrm{p}=0,215$ \\
\hline BMI & $\mathrm{p}=0,082$ & $\mathrm{p}=0,051$ & $\mathbf{p}=\mathbf{0 , 0 0 0}$ & $\mathrm{p}=0,319$ & $\mathrm{p}=0,131$ \\
\hline
\end{tabular}

Sementara untuk hubungan $\mathrm{VO}_{2} \max$ dengan level aktivitas fisik dan BMI pada metode skinfold, nilai signifikansi yang diperoleh $\mathrm{p}>0,05$ sehingga tidak terdapat hubungan antara $\mathrm{VO}_{2}$ max yang dikonsumsi saat pengukuran dengan BMI dan aktivitas fisik. Hal ini disebabkan pada perhitungan
BMI, melibatkan perhitungan berat badan yang meliputi berat badan total. Berat ini termasuk berat tulang, cairan tubuh, dan organ tubuh lainnya. Semakin kecil nilai berat badan seseorang bukan berarti semakin kecil tebal lapisan kulit yang dimiliki. 
Tabel 2. Korelasi $\mathrm{VO}_{2}$ max dengan Jenis kelamin dan BMI

\begin{tabular}{|l|l|}
\hline \multicolumn{1}{|c|}{ RELATED FACTOR } & \multicolumn{1}{c|}{$\begin{array}{c}\text { CORRELATION } \\
\text { COEFFICIENT }\end{array}$} \\
\hline $\begin{array}{l}\text { VO2 MAX SKINFOLD \& JENIS } \\
\text { KELAMIN }\end{array}$ & 0,803 \\
\hline $\begin{array}{l}\text { VO2 MAX BMI \& JENIS } \\
\text { KELAMIN }\end{array}$ & 0,838 \\
\hline $\begin{array}{l}\text { VO2 MAX ASTRAND \& JENIS } \\
\text { KELAMIN }\end{array}$ & 0,292 \\
\hline VO2 MAX ASTRAND \& BMI & $-0,677$ \\
\hline PFI \& JENIS KELAMIN & 0,669 \\
\hline
\end{tabular}

Melalui uji statistika Kruskal-wallis, diperoleh nilai signifikansi hubungan antara jenis kelamin, Body Mass Index, dan level aktivitas fisik dengan $\mathrm{VO}_{2}$ max pada setiap jenis pengukuran kebugaran aerobik yang dapat dilihat pada Tabel 1.

Pada uji skinfold, terdapat perbedaan jumlah $\mathrm{VO}_{2}$ max pada masing-masing jenis kelamin dengan nilai korelasi yang cukup kuat $(\mathrm{r}=0,803)$ seperti yang ditunjukkan pada Tabel 2. Laki-laki memiliki $\mathrm{VO}_{2} \max$ lebih tinggi daripada perempuan. Hal ini disebabkan perempuan memiliki persentase lemak yang tersimpan lebih tinggi. Tidak hanya itu, perempuan juga memiliki lemak esensial yang lebih tinggi yang terdapat pada sumsum tulang, central nervous sistem, mammary glands, dan beberapa organ lainnya (Baumgartner dkk, 2007).

Melalui uji BMI, nilai signifikansi $\mathrm{p}<0,05$ antara volume $\mathrm{O}_{2}$ maksimal dengan jenis kelamin, yaitu terdapat perbedaan jumlah $\mathrm{VO}_{2}$ max pada masing-masing jenis kelamin ( $\mathrm{r}$ $=0,838$ ). Hal ini disebabkan laki-laki memiliki struktur tulang dan tingkat pertumbuhan yang berbeda dengan perempuan.

Dari hasil uji sepeda Astrand, nilai signifikansi $\mathrm{p}<0,05$ antara volume $\mathrm{O}_{2}$ maksimal dengan jenis kelamin dan $\mathrm{BMI}$, sehingga pengambilan keputusannya adalah terdapat perbedaan jumlah $\mathrm{VO}_{2} \max$ pada masingmasing jenis kelamin dan kategori BMI dengan nilai korelasi yang lemah dan arah korelasi positif untuk jenis kelamin $(r=0,292)$ serta nilai korelasi yang kuat dengan arah korelasi negatif untuk BMI $(\mathrm{r}=-0,677)$. Nilai korelasi tersebut menunjukkan bahwa lakilaki cenderung memiliki nilai $\mathrm{VO}_{2}$ max yang lebih tinggi daripada perempuan. Hal ini juga berarti semakin besar nilai BMI atau semakin tinggi level kategori $\mathrm{BMI}$, nilai $\mathrm{VO}_{2}$ max pada pengukuran ini semakin rendah. Perbedaan paling signifikan terjadi antara responden dengan kategori BMI normal dan overweight, seperti hasil analisis Post Hoc dengan uji MannWhitney yang ditunjukkan pada Tabel 3.

Tabel 3. Analisis Post Hoc pada Uji Sepeda Astrand

\begin{tabular}{|l|l|}
\hline \multicolumn{2}{|c|}{ KELOMPOK } \\
\hline $1 \& 2$ & 0,006 \\
\hline $1 \& 3$ & 0,004 \\
\hline $1 \& 4$ & 0,134 \\
\hline $2 \& 3$ & 0,002 \\
\hline $2 \& 4$ & 0,092 \\
\hline $3 \& 4$ & 0,134 \\
\hline $1=$ underweight; $2=$ normal; \\
$3=$ overweight; $4=$ obese 1
\end{tabular}

Pada pengukuran $\mathrm{VO}_{2}$ max melalui uji lari pada lintasan treadmill, nilai signifikansi $\mathrm{VO}_{2}$ max dengan ketiga faktor $\mathrm{p}>0,05$ sehingga tidak ada hubungan yang signifikan antara ketiga faktor dan $\mathrm{VO}_{2}$ max. Nilai $\mathrm{VO}_{2}$ max antara laki-laki dan perempuan tidak jauh berbeda secara keseluruhan karena waktu tempuh pada uji lintasan treadmill pada masing-masing jenis kelamin juga tidak jauh berbeda

Grafik perbandingan rata-rata $\mathrm{VO}_{2}$ max pada metode Astrand, treadmill, skinfold, dan BMI ditunjukkan pada Gambar 3.

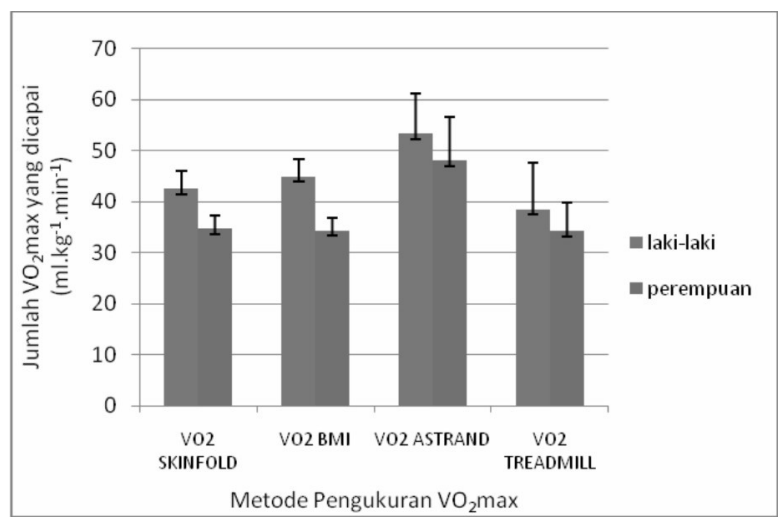

Gambar 3. Perbandingan Rata-rata $\mathrm{VO}_{2}$ max pada Empat Metode 
Pada pengukuran kebugaran aerobik melalui Hardvard Step Test, nilai signifikansi $\mathrm{p}<0,05$ antara nilai PFI dengan jenis kelamin, sehingga terdapat perbedaan nilai PFI pada masing-masing jenis kelamin. Laki-laki memiliki nilai PFI yang lebih tinggi daripada perempuan. Hal ini dapat disebabkan pada uji Hardvard Step Test melibatkan kekuatan otot, di mana kekuatan otot laki-laki lebih besar daripada kekuatan otot perempuan. Bahkan dengan intensitas latihan yang sama kekuatan otot perempuan kurang 30\% dari kekuatan otot laki-laki. Hal ini dialami setelah masa puber. Kekuatan otot wanita hanya sekitar $3 / 4$ dari pria (Astrand dkk, 2003). Sementara untuk faktor BMI dan aktivitas fisik tidak memberikan pengaruh yang signifikan.

Nilai rata-rata $\mathrm{VO}_{2}$ max yang dicapai pada masing-masing metode bervariasi, seperti pada Tabel 4.

Tabel 4. Perbandingan Nilai Rata-rata dan Standar Deviasi $\mathrm{VO}_{2} \max$ Masing-masing Metode

\begin{tabular}{|c|c|c|c|}
\hline & & LAKI-LAKI & PEREMPUAN \\
\hline \multirow{4}{*}{$\begin{array}{l}\text { MEAN } \\
\left(\mathrm{ml} \cdot \mathrm{kg}^{-1} \cdot \mathrm{min}^{-1}\right)\end{array}$} & $\mathrm{VO}_{2}$ MAX SKINFOLD & 42,49 & 34,63 \\
\hline & $\mathrm{VO}_{2} \mathrm{MAX} \mathrm{BMI}$ & 44,86 & 34,25 \\
\hline & $\mathrm{VO}_{2}$ MAX ASTRAND & 53,24 & 47,86 \\
\hline & $\mathrm{VO}_{2}$ MAX TREADMILL & 38,43 & 34,10 \\
\hline \multirow{4}{*}{ STDV } & $\mathrm{VO}_{2} \mathrm{MAX}$ SKINFOLD & 3,38 & 2,51 \\
\hline & $\mathrm{VO}_{2} \mathrm{MAX} \mathrm{BMI}$ & 3,45 & 2,46 \\
\hline & $\mathrm{VO}_{2} \mathrm{MAX}$ ASTRAND & 7,82 & 8,59 \\
\hline & $\mathrm{VO}_{2}$ MAX TREADMILL & 9,05 & 5,73 \\
\hline
\end{tabular}

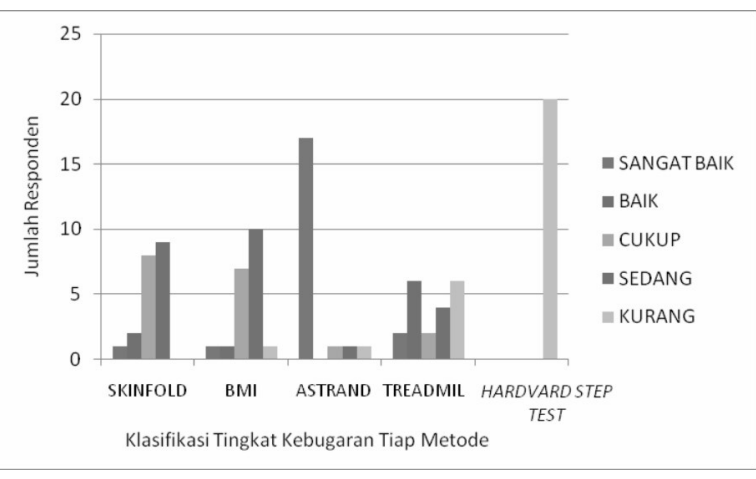

Gambar 4. Profil Kebugaran untuk Perempuan

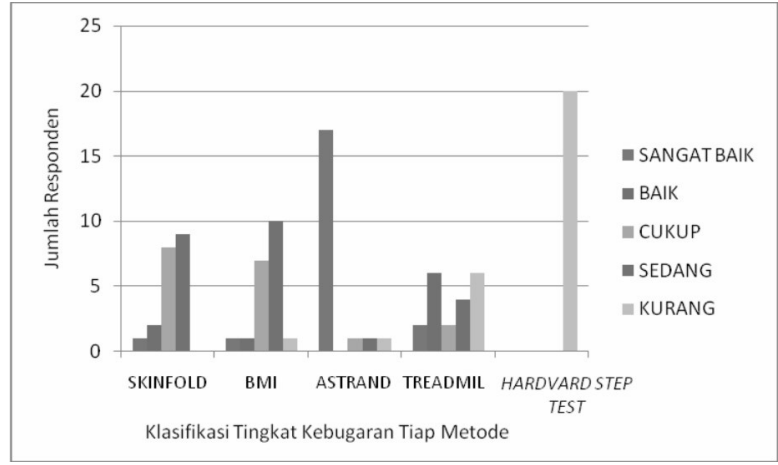

Gambar 5. Profil Kebugaran untuk Laki-laki

Variasi ini dapat disebabkan perbedaan unsur yang dimasukkan dalam perhitungan pengukuran. Untuk kebugaran yang diukur dengan metode nonexercise, tidak melibatkan usaha fisik dan parameter denyut jantung. Akan tetapi, metode ini tidak dapat mencapai tingkat kebugaran sebaik pada metode exercise.

Metode nonexercise lebih sesuai digunakan untuk subyek yang memiliki tingkat kesehatan jantung yang rendah dan kurang sesuai jika dipergunakan untuk subyek yang memiliki tingkat kesehatan yang tinggi (Astrand dkk, 2003). Sehingga dari Gambar 4 dan 5, metode yang paling tepat digunakan untuk mengukur tingkat kebugaran aerobik sesuai dengan kondisi jantungnya adalah metode Astrand dengan rata-rata $\mathrm{VO}_{2}$ max yang dicapai paling tinggi dibandingkan metode lain. Pada metode ini dilakukan pemberian work rate secara bertahap sesuai dengan kondisi denyut jantung submaksimal pada setiap enam menit, dengan kecepatan yang konstan, memberikan beban yang cenderung lebih konstan (constant 
force). Pembebanan yang bertahap dalam rentang waktu yang tidak terlalu cepat (tiap 6 menit) memberikan waktu penyesuaian bagi subyek untuk berpindah dari level beban yang lebih rendah menuju yang lebih tinggi karena emotional stress juga berpengaruh pada pengukuran. Semakin berat work rate semakin menambah efek gugup pada denyut jantung (Andersson, 2004). Maka dari itu, subyek dapat benar-benar mencapai kondisi submaksimal. Pada treadmill, penambahan beban relatif lebih cepat (tiap menit), sehingga subyek cenderung mengalami nervous stress pada denyut jantung, sehingga subyek berhenti sebelum mencapai kondisi $\mathrm{VO}_{2}$ yang benar-benar maksimal. Pada metode treadmill, peningkatan denyut jantung terjadi lebih cepat daripada sepeda Astrand karena terjadi gesekan antara permukaan telapak kaki dan permukaan lintasan lari yang menimbulkan panas, di mana panas permukaan akibat gesekan ini juga mempengaruhi peningkatan denyut jantung (Astrand dkk, 2003). Kondisi yang terlihat ekstrim juga ditunjukkan pada profil kebugaran melalui Hardvard Step Test. Jumlah subjek dengan kategori kebugaran "kurang" mendominasi kategori yang lain. Hal ini dapat disebabkan beban kerja yang diberikan lebih berat dari yang biasanya dan tanpa pemanasan yang intensif sebelumnya, frekuensi naik turun bangku Hardvard kurang maksimum, atau standar yang dipakai pada rumus ini merupakan standar dari luar negeri di mana orang barat dominan memiliki kapasitas kerja lebih dibandingkan orang Indonesia, misalnya karena faktor pemenuhan gizi atau perbedaan pola hidup dalam pekerjaan sehari-hari.

\section{SIMPULAN}

Faktor jenis kelamin sangat berpengaruh pada variasi tingkat kebugaran aerobik mahasiswa JTMI (pada metode skinfold, sepeda Astrand, Hardvard Step Test, dan $\mathrm{BMI})$. Faktor BMI berpengaruh pada tingkat kebugaran aerobik mahasiswa JTMI (pada metode sepeda Astrand). Faktor level aktivitas fisik tidak berpengaruh signifikan terhadap tingkat kebugaran arobik mahasiswa JTMI UGM.

Faktor jenis kelamin memiliki korelasi positif paling kuat dengan tingkat kebugaran aerobik melalui pengujian BMI $\left(r_{\mathrm{s}}=0,883\right)$. Laki-laki dapat mencapai $\mathrm{VO}_{2}$ max yang lebih tinggi daripada perempuan. Sementara itu, faktor BMI berbanding terbalik dengan perolehan $\mathrm{VO}_{2} \max$ (pada metode sepeda Astrand adalah $\left.\mathrm{r}_{\mathrm{s}}=-0,667\right)$. Semakin besar nilai BMI, maka semakin rendah $\mathrm{VO}_{2} \max$ yang diperoleh.

Hasil rata-rata $\mathrm{VO}_{2} \max$ (dalam ml.kg- ${ }^{-1}$. $\min ^{-1}$ ) yang dicapai dari masing-masing metode yaitu pada laki-laki untuk metode sepeda Astrand $=53,24 \pm 7,82$, treadmill $=$ $38,43 \pm 9,05, \quad \mathrm{BMI}=44,85 \pm 3,45$, skinfold $=$ $42,49 \pm 3,38$. Untuk perempuan, metode sepeda Astrand $=47,86 \pm 8,59$, treadmill $=$ $34,1 \pm 5,73, \mathrm{BMI}=34,25 \pm 2,46$, skinfold $=$ $34,63 \pm 2,51$, sehingga metode paling efektif ditinjau dari keoptimalan subyek mencapai $\mathrm{VO}_{2}$ max adalah metode Astrand dengan ratarata pencapaian tertinggi.

\section{DAFTAR PUSTAKA}

Andersson, D., 2004, The Astrand-Rhyming Test/Method Under The Magnifying Glass, Stockholm, Idrottshogskolan.

Astrand, P.O., Rodahl, K., dan Dahl, H.A., 2003, "Textbook of work Physiology Physiological Bases of Exercise Fourth Edition", Oslo, Human Kinetics.

Atmadja, D.S. dan Doewes, M., 1995, ACSM Panduan Uji Latihan Jasmani dan Peresepannya, Jakarta, Penerbit Buku Kedokteran EGC.

Baumgartner, T.A., Jackson, A.S., Mahar, M.T., dan Rowe, D.A., 2006, "Measurement for Evaluation in Physical Education and Exercise Science", New York: Mc Graw Hill.

Dahlan, M.S., 2009, Statistik untuk Kedokteran dan Kesehatan, Jakarta, Salemba Medika. 
Grandjean, E., 1986, "Fitting the Task to the Man", London, Taylor \& Francis.

Indriati, E., 2011, Antropometri Untuk Kedokteran, Keperawatan, Gizi, dan Olahraga, Klaten, PT Intan Sejati.

IPAQ Research Committe, 2005, “Guidelines for Data Processing and Analysis of The International Physical Activity Questionnaire (IPAQ)".
Lutan, R., 2001, Asas-asas Pendidikan Jasmani, Jakarta, Dirjen Olahraga Depdiknas.

Sajoto, M., 1988, Pembinaan Kondisi Fisik dalam Olahraga, Jakarta, Departemen Pendidikan dan Kebudayaan.

Widaninggar, W.M., Suharto, Soekaptiadi, S., dan Hutapea, Jintan, 2002, Ketahuilah Tingkat Kesegaran Jasmani Anda, Jakarta, Departemen Pendidikan Nasional Pusat Pengembangan Kualitas Jasmani. 